\title{
Treatment of severe and persistent mental illness in a community residential alternative was effective
}

\author{
Fenton WS, Mosher LR, Herrell JM, et al. Randomized trial of general hospital and residential alternative care for patients with \\ severe and persistent mental illness. Am J Psychiatry 1998 Apr;155:516-22.
}

\section{Question}

In voluntary patients with severe, persistent mental illness, is treatment in an acute residential alternative as effective as in a hospital psychiatric ward?

\section{Design}

6 month randomised controlled trial.

\section{Setting}

A local public health authority in Maryland, USA.

\section{Patients}

119 patients (mean age $37 \mathrm{y}, 52 \%$ men) who were judged by clinicians to need inpatient hospital care but not acute medical care or detoxification, had Medicaid or Medicare funding, and agreed to accept voluntary placement. Patients who had acute psychosis, depression, suicidal or homicidal tendencies, or substance abuse were included. Follow up was $100 \%$ at discharge and $95 \%$ at 6 months.

\section{Intervention}

Patients were randomised to a community residential alternative $(n=69)$ or a psychiatric ward of a general hospital $(n=50)$. The community residential alternative was a home with 8 beds; a supportive environment was provided for patients who continued to see outpatient treatment providers and community supports. Hospital care included medical assessment, individual psychotherapy, group therapy, and pharmacological management.

\section{Main outcome measures}

Main outcomes were changes in patient symptom severity, patient satisfaction with treatment, and number of discharges to the community. Secondary outcomes were psychosocial functioning, service use, and life satisfaction within 6 months of treatment.

\section{Main results}

Length of stay was longer for patients in the residential alternative than for patients in the hospital (18.7 $v 11.7$ days, $\mathrm{p}<0.002)$. Patients' symptom severity decreased in both treatment groups over time ( $\mathrm{p}<0.0001$ for both groups) and did not differ between treatments. Overall patient satisfaction did not differ between treatments, although patients in the community residential alternative were more satisfied with their food than were those in hospital care. $91 \%$ of all patients were discharged to the community. Treatment failure rates did not differ between treatments (table). No serious adverse events occurred among the 9 patients transferred from the residential alternative to an inpatient facility. No differences between treatments occurred in acute care use, psychosocial functioning, or patient satisfaction with life and health at 6 months follow up; 1 patient in the community residence alternative group committed suicide after discharge.

\section{Conclusion}

In voluntary patients with severe, persistent mental illness, treatment of an acute episode in a community residential alternative was as effective as treatment in a hospital psychiatric ward.

Community residential alternative v hospital psychiatric ward at discharge*

\begin{tabular}{lllll}
\hline Outcome & Community & Hospital & RRI (95\% CI) & NNH (CI) \\
\hline $\begin{array}{c}\text { Treatment } \\
\text { failure }\end{array}$ & $13 \%$ & $4 \%$ & $226 \%(-15$ to 1208) & Not significant \\
\hline
\end{tabular}

*Abbreviations defined in glossary; RRI, NNH, and CI calculated from data in article.

Source of funding: Substance Abuse and Mental Health Services Administration.

For correspondence: $D r W S$ Fenton, Chestnut Lodge Research Institute, 500 West Montgomery Avenue, Rockville, MD 20850, USA. Fax +1 3013090915.

\section{Commentary}

This study by Fenton $e$ al joins the ranks of numerous well designed trials that have shown the effectiveness of alternatives to inpatient admission, for example home treatment, ${ }^{1}$ assertive community treatment, ${ }^{2}$ and partial admission to hospital. ${ }^{3} \mathrm{It}$ is 1 of the few randomised studies of a crisis residential alternative. Elements of crisis response systems have not been rigorously evaluated so this is a valuable addition to our knowledge about service delivery.

This well designed study shows that safe and effective treatment can be given to severely disabled people during acute episodes in a home-like environment with on site non-medical staffing. Unfortunately, an economic analysis was not included. The amount of money saved is difficult to assess without more infor- mation about treatment and support services used during longer stays in the crisis residence. The small difference in patient satisfaction is somewhat surprising because other studies show that nonhospital alternatives are typically preferred. ${ }^{4}$

Clinicians should note that no exclusion criteria related to psychopathology were used and that suicidal and acute psychotic behaviour could be managed in a non-hospital setting; this raises exciting possibilities for the reduction of stigma and isolation that can result from repeated admission to hospital. Unfortunately, programmes such as this one may be limited, even though they are feasible and effective. Hospital policies and implementation of alternatives to inpatient admission consistently lag far behind what research evidence defines as best practice. A factor beyond cost savings that might counter this deficiency would be more positive attitudes and advocacy on the part of front line healthcare providers willing to sacrifice personal convenience and alter their work routines to improve the delivery of care.

Paula Goering, RN, PhD University of Toronto Toronto, Ontario, Canada

1 Marks IM, Connolly J, Muijen M, et al. Br J Psychiatry 1994;165:179-94.

2 Mueser KT, Bond GR, Drake RE, et al. Schizophr Bull 1998;24:37-74.

3 Hoge MA, Davidson L, Hill WL, et al. Hosp Community Psychiatry 1992;43:345-54.

4 Wasylenki D, Gehrs M, Goering P, et al. Community Ment Health J 1997;33:151-62. 